\title{
Consideration of Problem Formulation and Option Assessment (PFOA) for Environmental Risk Assessment: Bt Cotton in Vietnam
}

\author{
NGuYỄN Văn UYỂn, Phan Văn ChI, NGUYễN Văn Bộ, \\ Hoàng Thanh Nhàn, Lê Quang QuyÉn, NGuYễN XuÂn \\ Hồng, Lê Minh Sắt, Arjen Wals, Deise M.F. Capalbo \\ and Kristen C. Nelson
}

Throughout the world, countries are discussing the role genetically modified organisms (GMOs) will have in their future. Each country begins the discussion at a different starting point, depending on distinct historical, economic, social and environmental factors. For some, GMOs are a new technology that should be used based on market principles - if it is a viable product, it will survive and contribute to economic growth. For others, it is a question of considering longterm risks and uncertainties before making short-term decisions. Precaution is the guiding principle for these decision makers. Still others are caught in the conflict between these points of view as they make decisions regarding the introduction of GMOs to their countries. Decision makers and citizens have the right and responsibility to design their own policy and regulatory systems to address GMOs.

Vietnam is an agriculture-based developing country and, as such, the export of agricultural commodities is and will play an important role in its economy. Despite the fact that Vietnam joined the Cartagena Protocol officially on 19 January 2004, the conflict over GMOs in the world, as reflected by mass media reporting, has created considerable hesitation among policy makers as they formulate and adopt Vietnam's National Biosafety Guidelines. Several meetings and seminars were organized to stimulate discussion between scientists and decision makers, including well-known foreign scientists. These events were designed to encourage deliberation and reflection about the official point of view of the Vietnam Government on the GMO issue. 
This chapter is a result of reflection by the authors, begun in sessions held in Ho Chi Minh City, Vietnam, 1-5 April 2004 and continued over a 2-year period. One critical component focused on deliberation as a core element of environmental risk assessment. In this case, it is clear that Vietnam must create a responsive system to facilitate social recognition of the risks and participate in the selection of acceptable choices. At its core, the discussion focuses on the critical societal need that will be addressed by the GMO, i.e. what needs will be satisfied and at what risk? Societal risk requires societal reflection. A deliberative process with multi-stakeholder participation allows members of society to participate in the evaluation of critical needs and risks. A cross-section of society farmers, consumer groups, industry, environmental representatives, policy makers, etc. - must have a vehicle to express their concerns and evaluate the future alternatives for addressing basic needs. Finally, this deliberative process will be increasingly important for resource-scarce nations if public investment is involved, because a comparative reflection by a cross-section of society may be beneficial in the prioritizing and targeting of resources. To meet these requirements, the Problem Formulation and Options Assessment (PFOA) (Nelson et al., 2004; Capalbo et al., 2006; Nelson and Banker, 2007) concept is presented in this chapter.

\subsection{What is the PFOA?}

The PFOA is a science-based multi-stakeholder process to formulate problems and assess options as a basis for environmental risk assessment when a country is considering the introduction of a genetically modified organism (GMO) into a specific environment (see Nelson et al., 2004; Capalbo et al., 2006; Nelson and Banker, 2007).

The goals of this process are to help multiple stakeholders to assess their needs, evaluate the risks related to multiple future options and to make recommendations to decision makers about policies to reduce societal risks and enhance the benefits provided by adoption of the GMOs. To fulfil these objectives, the authors suggest that a PFOA conducted in Vietnam should meet the following requirements:

\section{All stakeholders' input should be emphasized}

The PFOA should have all stakeholders' input in the identification of priorities, assessment of possible harms, formulating of options and recommendations for a decision by government authorities. All stakeholders, decision makers, environment representatives, farmers and consumer groups have the right to express their concerns about the use of GMOs and to contribute to the formulation of appropriate GMO policies and decisions for the biosafety of their country.

2. The PFOA should be legitimate to the public

The process should not be considered as the private work of one person or one group of stakeholders. It should be legitimate, so public contributions are possible and citizens know what is happening in the environmental risk assessment, management and communication. 


\section{The PFOA should be transparent}

Transparency in the PFOA means it should be conducted to facilitate public awareness of the problems and benefits, while encouraging the public's eagerness to contribute to formulating options and evaluating risks.

4. The PFOA should be sanctioned formally

Vietnamese authorities should recognize the contribution the PFOA makes to environmental risk assessment and use the recommendations from the stakeholder discussions to inform their decisions.

5. PFOA data and information should be driven with professional expertise In order for the decision to be well informed, the discussion is best served when driven by sound, scientifically guided assessment and review. A robust environmental risk assessment clearly delineates when scientific knowledge, information and analysis can respond to key questions effectively.

6. The PFOA should be country specific

The PFOA is country specific and should be conducted with strong references to the local social and natural conditions in Vietnam. Not only do countries have different starting points with regards to the introduction of new technologies such as GMOs, they also differ in the way the discussions about the GMOs' introduction are conducted and in the way the outcomes of such discussions influence the decision making process.

In many cases, the previously mentioned characteristics are the ideal requirements and some may face constraints and limitations during implementation. The PFOA organizers may find there is limited information, financial support, or political will to meet all these characteristics. Every effort can be made to recognize the ideal characteristics while working with what is available or feasible at the time, always planning for improvements in the future.

The PFOA is started with the Initiation of a Proposal to the competent authority (CA) of the relevant ministry for risk assessment of a specific introduction of $\mathrm{GMO}(\mathrm{s})$ to the environment. For example, the relevant ministry will depend on whether the GMO is a crop, fish, tree, or a medicine. The PFOA could be conducted by the relevant ministry, when the CA decides to proceed with an evaluation of a GMO. The following section presents a brief overview of the PFOA methodology.

\subsection{Relation of the PFOA to Environmental Risk Assessment ${ }^{1}$}

Practitioners and scholars have tested numerous techniques that serve as a methodological foundation for the PFOA in environmental risk assessment (Grimble and Wellard, 1997; Kessler and Van Dorp, 1998; Loevinsohn et al., 2002, to name a few). Two crucial steps in risk assessment are addressed by many of these techniques and the PFOA is designed specifically to address

\footnotetext{
${ }^{1}$ We provide a few definitions to support the discussion of risk assessment and PFOA in Vietnam (Box 3.1).
} 
them. The first critical step in risk assessment is problem identification (NRC, 1983, 1996). What is the problem that the GMO technology is going to address? What is the scope of the problem, how is it defined? Problem identification frames the entire risk assessment. A second critical step is the identification of potential alternative solutions to the problem and their possible risks (NRC, 1983, 1996). The proposed action, in this case, the use of Bt cotton in Vietnam, is never the only possible way to address the problem. Risk assessment depends entirely on an appropriate specification of alternatives (including taking no action and doing nothing), so that comparative risk can be assessed and appropriate controls for risk assessment science can be defined and used.

The PFOA is comprised of specific brainstorming, discussion and analytical components. First, formulating the problem serves as the core foundation. The problem is defined as an unmet need that requires change. This is the identified problem and its effect, which results in an unmet need that requires change. Basic human needs are identified most commonly as food, shelter and safety. For example, a particular agricultural pest may reduce yields in a crop that is an important staple of a nation's population. If pest damage results in extreme food shortages for a large per cent of the population, this unmet need threatens food security and requires change. Once the needs for food, shelter and safety are met, individuals can expand their interests to include numerous options for well-being. These interests will differ from one individual to another and from one group to another.

After a problem is defined, the PFOA requires a comparative approach to risk assessment. The participants clarify the relative importance of this problem as compared to other problems or issues. Once the group agrees the problem is sufficiently important to merit an analysis, the range of future alternatives for solving the problem are compared in relation to their attributes, potential ability to address the problem, changes required to implement the option and potential adverse effects. The PFOA is assessing alternative future options, not for the current conditions against one option, but rather making a comparative assessment of options that exist and are in use now, that exist but are not used due to identifiable barriers, or new options that could exist in the future, such as the GMO. After a complete analysis by a multi-stakeholder group, a recommendation is made to decision makers to continue research and development (in some cases, risk assessment research) with the technology or to halt the development of the technology.

A science-based PFOA must be a deliberative process (Forester, 1999) designed to provide for social reflection and discussion about transgenic organisms. A sound deliberative process is transparent, equitable, legitimate and data-driven when possible (Susskind et al., 1999). Transparency allows for the open communication of information between all parties and easily accessible reporting of decisions to the public (Hemmati, 2002). Providing an equitable PFOA process means that information from the broadest spectrum of society must be included, with all stakeholders having the possibility to contribute. Civic society must perceive that there are sufficient avenues for input and consideration of diverse viewpoints and concerns. When transparency and equitable input are central to the process, the PFOA gains legitimacy in the public 
eye. This public legitimacy must be matched by traditional legitimacy or sanctioning by a formal political body that embeds the deliberative process. The deliberative process can be tied to a regulatory authority or legislative authority, but it must provide a means by which results from the PFOA inform government decision making and action. Finally, the foundation of the PFOA is a science-based inquiry. Questions are answered with data, impacts are assessed with valid indicators and the limits of our understanding are delineated clearly by a research agenda or procedures for taking uncertainty into account.

Again, each country will need to develop a country-specific deliberative process that fits the particular structure and authority of the relevant decision making bodies and implementing agencies. For many political systems in the world, the legitimating authority exists to incorporate the PFOA in a legislative or regulatory context, but there are debates about necessary modifications of policies and regulation for transgenic organisms (Munson, 1993; Miller, 1994; Hallerman and Kapuscinski, 1995; NRC, 2002). Depending on the legislative or regulatory situations, a PFOA can be incorporated into a public consultative process that is authorized by regulation, or it may be added as an alternative process, supported by civic society, that informs the debate in traditional decision making bodies, or it may be incorporated in existing decision making processes in order to make that process more inclusive, transparent and more science-based.

\subsection{Steps in Conducting a PFOA}

The Vietnam National Biosafety Regulation (BSR) ${ }^{2}$ was adopted officially by the Vietnam Government in August 2005 (Box 3.1). The National Action Plan on Biodiversity, approved in May $2007,{ }^{3}$ identifies as a major solution the '... active participation of people in biodiversity protection and biosafety management' as described in objective 3(b). 'To ensure the community's right and participation in the process of appraising investment policies, strategies, master plans, plans, programmes and projects concerning natural reserves and the biosafety decision making process'. Implementation of the PFOA is therefore an immediate, necessary action if these regulations are to be applied properly.

A PFOA normally consists of several steps: ${ }^{4}$

- Step 1: Problem Formulation

- Step 2: Prioritization and Scale of Problem

2 Decision No. 212/2005/QD-TTg promulgating the Regulation on Management of Biological Safety of Genetically Modified Organisms, Products and Goods originating from Genetically Modified Organisms, signed by Prime Minister Phan Van Khai, effective date 26 August 2005 (National Biosafety Regulations).

${ }^{3}$ Decision No. 79/2007/QD-TTg approving the National Action Plan on Biodiversity up to 2010 and Orientations towards 2020 for Implementation of the Convention on Biological Diversity and the Cartagena Protocol on Biosafety, signed by Prime Minister Nguyen Tan Dzung, effective date 31 May 2007.

${ }^{4}$ For a discussion of the PFOA Steps and Questions refer to Nelson et al., 2004; Capalbo et al., 2006; Nelson and Banker, 2007. 
Box 3.1. Terminology for risk assessment and PFOA in Vietnam

Terminology used in the Vietnam National Biosafety Regulations:

1. Biological safety means measures to manage safety in scientific research, technological development and assay; production, trading and use; import, export, storage and transportation; risk evaluation and management and grant of biological safety certificates for genetically modified organisms; products, goods originating from genetically modified organisms.

2. Gene means a unit of heredity, a segment of genetic material of an organism determining the particular characteristics of the organism.

3. DNA (deoxyribonucleic acid) means genetic material of an organism, shaped like a double helix and composed of many genes (units of heredity).

4. Gene transfer technology means the transter of a gene of one organism to another, forcing the DNA helix of the target organism to accept the foreign gene.

5. Genetically modified organisms mean animais, plants or microorganisms whose genetic structure has been altered by gene transfer technology.

6. Products or goods originating from genetically modified organisms mean products or goods created wholly or partly from genetically modified organisms.

7. Release of genetically modified organisms means the deliberate introduction into the environment of genetically modified organisms.

8. Risk assessment means the determination of the potential hazard and the extent of damage which has been caused or might be caused to human health, the environment and biodiversity in activities related to genetically modified organisms, particularly the use and release of genetically modified organisms; and to products and goods originating from genetically modified organisms.

9. Risk management means the application of safety measures to prevent, deal with and overcome risks to human health, the environment and biodiversity in activities related to genetically modified organisms, products and goods originating from genetically modified organisms.

Terminology used in the Problem Formulation and Options Assessment Handbook (Nelson and Banker, 2007):

1. Adverse effects: an undesired effect.

2. Deliberation: deliberation is a means by which a group of participants representing diverse interests in a governance process can work together to consider all relevant sides of an issue carefully in order to reach or move closer to a shared conclusion. It is characterized by an open sharing of ideas, listening to others, acknowledgement of diverse views and a spirit of collaboration.

3. Future alternative: any available option that could be implemented in place of what presently exists. This can include options that exist currently, options that will exist in the future and options that may exist in the future, whether or not they have yet been thought of.

4. Problem formulation: identifying the societal problem that the technology will address. Discussion focuses on whose problem is being addressed, whose problem should be addressed and what needs of the people identified are not being met by the present situation. The group assesses whether a problem truly exists based on extent, severity and relative importance compared to other problems. 


\section{Box 3.1. Continued}

5. Problem Formulation and Options Assessment (PFOA): methodology for conducting deliberative formulations of a problem and comparative assessments of future alternatives for addressing the problem relative to the biosafety evaluation of GMOs. A PFOA process helps stakeholders analyse collaboratively and advise on the identification of possible harms and the enhancement of potential benefits within the specific contexts for which a GMO is being considered. To this end, a PFOA relies on being transparent, inclusive of all appropriate stakeholders and rationally informed by the best available science.

6. Stakeholder representative: individuals that participate directly in the core deliberation of the PFOA on behalf of the interests of a particular stakeholder sector or grouping of sectors with shared interests. Stakeholder sectors must have their interests represented in a PFOA by a representative because it is not practical or effective to involve directly every individual member in the process.

\section{- Step 3: Problem Statement}

- Step 4: Authority decision to analyse options

- Step 5: Options

- Step 6: Attributes for Solving Problem

- Step 7: Changes Required and Anticipated for a Solution Option

- Step 8: Impact to the System

- Step 9: Authority decision about an option.

Vietnam depends on imported cotton for its textile industry $(90 \%$ of its raw material is imported). With the application of new varieties and modern integrated pest management (IPM) approaches, the area under cotton reached 30,000 ha, but has since declined to half this area. Obstacles to the development of cotton production are low prices and lack of an effective dry season production system, including suitable irrigation, varieties and IPM. Disease and pest damage is high, including lepidopteran pests.

We use Vietnam cotton as a case study for evaluating the merit, applicability and benefits of using the PFOA in environmental risk assessment. The participants in the trial run were the chapter authors. The authors do not represent the full diversity of stakeholders who may be involved in a PFOA, but they do represent a diversity of agency representatives and one farmers' union representative. An essential element of the PFOA process is the involvement of a broad spectrum of stakeholders whose representatives are allowed to contribute to the deliberative process. The identification and selection of the relevant stakeholders is particularly important for maintaining the public legitimacy of the proposed PFOA process. Representatives of all interested and affected stakeholders, both powerful and marginalized, need to be included in the deliberation process (see Nelson and Banker, 2007, for further explanation).

In this case study, Step 1: Problem Formulation, was done through brainstorming and debate. The group discussed that lepidopteran insects attacking cotton cause high yield losses (25-30\%) and that some lepidopteran species (Spodoptera exigua, Helicoverpa armigera) have become highly resistant to 
Box 3.2. Problem Formulation and Option Assessment (PFOA): example responses to Step 2 for Bt cotton in Vietnam, from the group discussion 2004

\section{Prioritization and scale considerations}

- Most farmers growing cotton are affected, especially poor farmers with smallholdings who lack proper application equipment, money to buy pesticides and knowledge of pest control. In particular, farmers in the central coastal region of Vietnam are affected heavily.

- Cotton companies who sign contracts with farmers (the company provides the means for growing cotton in return for the yields) lose investment.

- Cotton yield usually is reduced by $25-30 \%$.

- To protect cotton fieids from pests, farmers have to use more pesticides, leading to many health problems. In many areas, people suffer from allergies and many other diseases.

- The quality of life for agricultural workers, farmers and their families could be reduced.

- Soil, water and air in the cotton fields and surrounding areas have been polluted.

- The ecosystem of the whole region can also be affected.

most pesticides. Several members pointed out that most farmers growing cotton are using higher doses of pesticides, some of which have little or no affect on insect control and that, as a result, farmers were hesitant to switch to cotton because of the high risk involved. Some researchers have found that early season insecticide applications to control the spread of cotton blue disease by aphids induce outbreaks of $H$. armigera (see Chapter 2, this volume).

The case study discussion continued with Step 2: Prioritization and Scale of Problem (Box 3.2) and Step 3: Problem Statement; all designed to answer questions such as: Who is affected by the problem? And at what scale? What losses have occurred?

In Step 5: Options, different options to alleviate the problem(s) have to be identified and discussed based on scientific data and field test results. In our case study discussion, we identified several options for the control of Lepidoptera in cotton fields:

- Biological control (including the use of transgenic Bt cotton varieties)

- Chemical control

- Cultivating system

- $\quad$ IPM package = biological, chemical and cultivation system.

Of these, we selected two options for the process of evaluating how option assessment would work: Option A - Use of insect-resistant transgenic cotton varieties; and Option B - Generic IPM package including biological control + chemical con trol + cultivation management. Steps 6, 7 and 8: Option Assessment, are designed for a multidisciplinary assessment of options regarding different aspects. Again, in our case study of transgenic cotton introduction to Vietnam, we identified examples of assessment responses regarding the two options (Box 3.3). Questions in Step 6 provide a discussion of the technology attributes and barriers to adoption 
Box 3.3. Problem Formulation and Option Assessment (PFOA): example responses to Steps 6, 7 and 8 for Bt cotton in Vietnam, from the group discussion 2004

\section{Option A: Use of insect-resistant GM cotton varieties}

\section{Option B: IPM package Biological, chemical and cultivation management}

\section{Attributes of the option}

Characteristics: transgenic

Regions for use: all cotton growing areas

Barriers to technology adoption and efficacy:

- Seed cost (?) and source

- Adaptability of new varieties to local conditions

- Government authorization and intellectual property issues (risk assessment, permission for distribution and commercialization)

- Knowledge of farmers and acceptance

- Trade barriers (consumer concern)

Characteristics: integrated management system

Regions for use: central coastal region of Vietnam and similar regions

Barriers to technology adoption and efficacy:

- Difficulty in finding a good biocontrol measure

- Low acceptance by farmers to apply IPM

- Farmers' knowledge for applying IPM is limited

- Coordination of stakeholders across a region (farmers, local authorities, extension workers, companies...) is weak

- Applying biocontrol measures is costly and effect is slow (bioproduct is expensive)

- IPM is rather complex - some farmers may not apply it correctly

\section{Needed or anticipated changes to the system if using the option}

- Less pesticide use and pest-control cost

- Larger cotton growing area, especially in dry season

- More monoculture of some varieties
- Reduce use of pesticide

- Need for labour is increased

- Need IPM training for farmers and improved coordination of stakeholders

- Farmers are more independent from foreign input (seed, biopesticide)

\section{Possible effects of the technology option}

- Higher dependence of farmers on foreign seeds

- Biodiversity loss

- Dramatic change for non-target pests

- Breakdown of resistance

- Unforeseen other consequences (human health...)
- Working condition of farmers and environment is improved

- Sustainable practice

- Cost for production might be increased

- Knowledge of IPM is increased

and/or efficacy. Questions in Step 7 allow the PFOA participants to consider larger system changes from farm to societal scales. For example, participants evaluate anticipated or needed changes if a technology is implemented. Finally, questions in Step 8 allow the PFOA group to discuss possible adverse effects and benefits of the technology, with a special focus on environmental risks. 
At the end of the PFOA deliberation, participants make a recommendation to the CA in the relevant ministry, who is responsible for deciding whether to proceed with the GMO proposal. There are several ways to agree on a final PFOA recommendation. Some countries suggest that everyone has to agree on the recommendations (consensus); other countries say most of the people have to agree (two-thirds voting in support); and others say a simple majority is fine. In Vietnam, the appropriate approach is recommendation by consensus. It is best to continue discussion and work for clarification, while focusing on matters where there are disagreements. This approach has been accepted as a working principle in meetings of the Association of South-east Asian Nations (ASEAN) by member countries on many topics. For PFOA recommendations, it is best to achieve a consensus opinion.

\subsection{Suggested Sources of Information and Scientific Data}

There are many sources of information and scientific data that would be helpful in answering the PFOA questions and assisting in discussion. General national level data on agriculture can be found in the Vietnamese General Office for Statistics and the Ministry of Agriculture and Rural Development (MARD). Provincial Departments of Agriculture and Rural Development could provide substantial farm-scale information. The Vietnamese Ministry of Natural Resources and Environment (MONRE) could provide basic information about biodiversity and ecosystem studies.

In relation to cotton, the Vietnam Cotton Company is a good source for information on production, cropping systems, processing and agricultural technology. The Vietnamese Textile and Garment Company manages data on fibre demand, import and export markets, as well as local markets.

The Plant Protection Department of MARD can provide pest and disease statistics and losses due to pesticide poisonings. The Nhaho Research Institute for Cotton and Agricultural Development and the Plant Protection Research Institute are another good source for scientific studies on pests, diseases and GMO testing. Information related to general biotechnology issues can be found in the Biotechnology Institute, the Agricultural Genetics Institute and the Cuulong Delta Rice Research Institute.

In general, information necessary for risk assessment can be found in a variety of ministries, depending on the nature of the questions.

\subsection{Challenges and Recommendations for Implementing PFOA for Environmental Risk Assessment in Vietnam}

After discussion of the PFOA process, using the case study on Bt cotton and learning from the experiences of Kenya and Brazil, we identified the challenges/ questions and recommendations for implementing PFOA in Vietnam that are listed in Table 3.1. 
Table 3.1. Challenges/questions and recommendations for implementing PFOA in Vietnam.

Challenges
Should the PFOA play a role?
Who is responsible for organizing the
PFOA in Vietnam?
How can we increase public awareness
about GMOs?

How can we coordinate the process involvement of different actors?

How can we get groups actively involved?

Time, money and energy?

How can we get data, information and expertise to improve the process?

How can we get stakeholder cost-benefit analysis?

How can we establish criteria for choosing the best option and who does it?

How can we deal with diversity in the way different groups think and value? Are all ways equal or are some better than others?

Who decides?

When does the PFOA stop?

The PFOA should be considered and applied in the whole process of making a decision.

See 'Decision making process' scheme including: information, consultation, decision.

Education and training on GMO risk assessment, PFOA for policy makers, decision makers, researchers and built-in communication with mass media in order to reach the general public.

Establish a National Biosafety Committee that includes representatives of all relevant ministries and social organizations.

Enhance people's awareness of their options to influence the decision making process and provide incentives for public participation.

Applicant should assist in paying for the PFOA consultation.

The Competent Authority (CA) of the relevant ministry will consider the PFOA questions and consult with related organizations.

Information from stakeholders on data should be compiled and reported by the CA.

The CA Technical Group develops criteria based on health, environmental, economic and social concerns.

Raise awareness within the public on a comprehensive understanding of all aspects of GMOs.

The CA.

No conclusive recommendation.

\subsection{Decision Making Scheme}

The final step of the PFOA (Step 9) is the CA decision about the GMO proposal. This step is presented schematically in Fig. 3.1. The CA uses information gathering and sharing based on environmental risk assessment research and the PFOA deliberation to make their decision, as well as campaigns to inform the public about GMOs and the particular decision. Then the CA proceeds with consultation by reviewing the PFOA deliberations and recommendations, as well as other legal requirements for public consultation. Based on the foundation of information and consultation, the CA proceeds with a decision to recommend or decline the GMO proposal to the National Biosafety Committee (NBC). As of October 2007, no decision had been made about the 


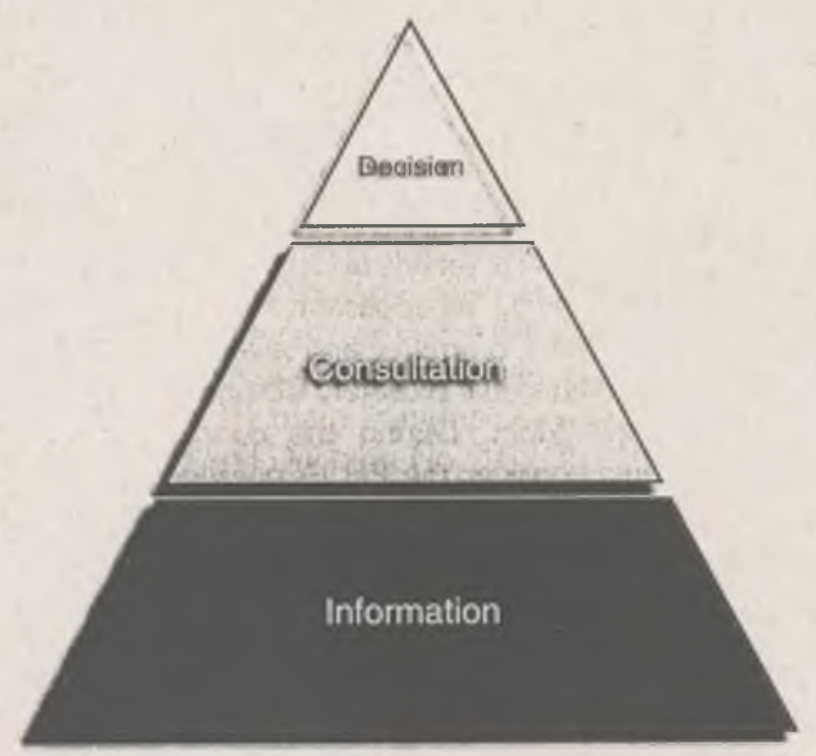

Fig. 3.1. PFOA deliberation and decision making regarding the GMO proposal as part of Vietnam's governance system.

make-up of the NBC, but Decision No. 102/2007/QD-TTg, ${ }^{5}$ effective July 2007 , requires the CAs to clarify roles and responsibilities for biosafety, as well as develop biosafety regulations. CAs include the Ministry of Natural Resources and Environment (MONRE), the Ministry of Agriculture and Rural Development (MARD), the Ministry of Science and Technology (MOST), the Ministry of Health $(\mathrm{MoH})$ and the Ministry of Industry and Trade (MIT). ${ }^{6}$

The CA of the relevant ministry will conduct the PFOA, consider the PFOA recommendations and consult with related organizations. For example, the CA of MARD will be responsible for the risk assessment of projects related to agriculture. Since most of the primary ministries had representatives involved in our discussions during 2005 , these suggestions were made with an understanding of the potential responsibilities and relationships of different agencies. Overall, there should be three phases to assessing a GMO.

The first phase of the environmental risk assessment (ERA) process would focus on information (Fig. 3.1). The GMO applicant would prepare documentation, including:

- Request for planting/rearing/commercializing a GMO;

- Risk assessment and risk management report;

${ }^{5}$ Decision No. 102/2007/QD-TTg promulgating Comprehensive Plan to Strengthen Management Capacity in Biosafety of GMOs, Goods and Products originating from GMOs until 2010, as well as Implementation of Cartagena Protocol on Biosafety, signed by Prime Minister Nguyen Tan Dzung, effective date 11 July 2007. http://antoansinhhoc.vn (Vietnamese and English translation).

${ }^{6}$ Decision No. 102/2007/QD-TTg, see above. 
- Relevant documents supporting their plan for planting/rearing or commercialization.

All these documents would then be submitted to the CA of the relevant ministry.

The second phase focuses on consultation, which ranges from a simple comment period to a more active process of deliberation represented by the PFOA. The CA would establish a Technical Group to review and evaluate all the information and data provided by the applicant. At the same time, the CA would establish a Ministerial Biosafety Committee and seek comment from relevant ministry representatives. The Ministerial Biosafety Committee might include MONRE, MOST, MARD, MT and MoH. During the consultation, the Ministerial Biosafety Committee would consider the PFOA questions/recommendations and consult with the relevant organizations. Finally, the Ministerial Biosafety Committee would review all findings from the Technical Group, the PFOA recommendations and conduct a general public consultation. From this, they would make a recommendation to the Minister of the Competent Authority regarding whether or not to permit development, planting, or commercialization of the GMO.

Finally, in the third phase, the CA Minister would decide whether to recommend supporting or declining the petition and pass along their recommendation to the National Biosafety Committee. After the National Biosafety Committee makes a decision, the $\mathrm{CA}$ would then inform the Applicant and the Biosafety Clearing House $(\mathrm{BCH})$ of MONRE about the decision.

\subsection{Conclusions}

Vietnam is entering a new, historic era in its development with basic reforms to its economy policy. As a result, foreign investment is expected to reach US $\$ 15$ billion in 2007 and, over the next 5 years, Gross Domestic Product (GDP) is forecast to increase by more than $8 \%$ annually. With the growth in the agricultural sector, within a global context, Vietnam is considering accelerating the introduction of GMOs to its agricultural system and environment.

Industrialization and modernization of rural agriculture have been given priority by government planners, with science and technology envisioned as the driving force. In January 2006, the Prime Minister issued a decision approving a critical programme of biotechnology development and implementation as a tool for agricultural and rural development through $2020 .{ }^{7}$ State authorities view biotechnology, the key element of which is the introduction of GMOs in agricultural sectors, as promising important niche solutions to many problems in the future.

At the same time, Vietnamese decision makers are aware of the global debate about GMOs. Many nations and scholars critique the argument that biotechnology is a necessary component of modern agriculture. They suggest it is still unclear how important this technology will prove to be. For example,

${ }^{7}$ Decision No. 11/2006/QD-TTg approving the key programme on development and application of biotechnology in the domain of agriculture and rural development up to 2020 , signed by Prime Minister Phan Van Khai, effective date 12 January 2006 
the European Union countries have varying acceptance of the production and use of GMO products. Considering the rapid changes in points of view towards GMOs and the pressure for Vietnam to modernize its agriculture, the mass introduction of some GMOs into Vietnamese agriculture is likely to be only a matter of time, most likely in the very near future. But the Vietnamese government wants to introduce GMOs in a safe manner, so that the environment does not sustain irreversible damage and the products can be used safely.

Several events suggest the government is preparing the policy and regulatory foundation for GMO technologies. Vietnam signed the Cartagena Protocol in 2004 and issued the Vietnam National Biosafety Regulation ${ }^{8}$ in August 2005. Decision No. $79^{9}$ and Decision No. $102^{10}$ in 2007 go on to require the development of biosafety regulations with coordination among ministries and a clarification of roles and responsibilities. On the economic front, some in Vietnam argue that the introduction of GMOs is an economic necessity for keeping up with regional and international trends in the modernization of agriculture, as well as the protection of the environment. In general, the introduction of GMOs into Vietnamese agriculture is considered a key approach for establishing a modern, sustainable agriculture, by 'Developing biotechnology for the benefit of sustainable development of agriculture, forestry and fishery, as well as the protection of human health and the living environment'. ${ }^{11}$

As a guiding principle for decision makers worldwide, the application of Problem Formulation and Option Assessment (PFOA) should be considered as a critical step that will assist Vietnamese authorities in making any decision, from denying to giving permission for a GMO release. PFOA benefits Vietnamese decision making by providing a science-based, multi-stakeholder process to formulate problems and assess options as a basis for ERA when a country is considering the introduction of a GMO. Public awareness and multi-stakeholder participation in the whole process are the main benefits of a PFOA approach. Before giving permission for the introduction of any GMO to Vietnam, the government authorities would have to be sure that all environmental risks have been assessed fully and clearly on a scientific basis with the full participation of all the stakeholders that would be affected, namely the companies, the scientists, the farmers and the representatives of the general public in the case of Bt cotton. The decision is made only after getting full information on risk identification and ample consultation on management alternatives (options assessment) from the concerned scientific and management institutions.

Though there are many debates in international and national meetings about risk assessment and risk management concerning GMOs, Vietnam clearly benefits from the experiences of other countries where PFOA has been considered. This will help to reduce conflict associated with misunderstandings and increase the effectiveness of GMO management, assuring transparency and public acceptance.

${ }^{8}$ Decision No. 212/2005/QD-TTg, see above.

9 Decision No. 79/2007/QD-TTg, see above.

${ }^{10}$ Decision No. 102/2007/QD-TTg, see above.

${ }^{11}$ Resolution 18/CP on Development of Biotechnology in Vietnam to 2010, signed 11 March 1994. 


\section{References}

Capalbo, D.M.F., Simon, M.F., Nodari, R.O., Valle, S., Dos Santos, R.F., Coradin, L., Duarte, J. de O., Miranda, J.E., Dias, E.P.F., Le Quang Quyen, Underwood, E. and Nelson, K.C. (2006) Consideration of problem formulation and option assessment for Bt cotton in Brazil. In: Hilbeck, A., Andow, D.A. and Fontes, E.M.G. (eds) Environmental Risk Assessment of Genetically Modified Organisms, Volume 2: Methodologies for Assessing Bt Cotton in Brazil. CAB International, Wallingford, UK, pp. 67-92.

Forester, J. (1999) The Deliberative Practitioner: Encouraging Participatory Planning Processes. MIT Press, Cambridge, Massachusetts.

Grimble, R. and Wellard, K. (1997) Stakeholder methodologies in natural resource management: a review of principles, contexts, experiences and opportunities. Agricultural Systems 55, $173-193$.

Hallerman, E.M. and Kapuscinski, A.R. (1995) Incorporating risk assessment and risk management into public policies on genetically modified finfish and shellfish. Aquaculture 137(1-4), 9-17.

Hemmati, M. (2002) Multi-stakeholder Processes for Governance and Sustainability: Beyond the Deadlock and Conflict. Earthscan Publications Inc., London.

Kessler, J. and Van Dorp, M. (1998) Structural adjustment and the environment: The need for an analytical methodology. Ecological Economics 27, 267-281.

Loevinsohn, M., Berdegué, J. and Guijt, I. (2002) Deepening the basis of rural resource management: learning processes and decision support. Agricultural Systems 73, 3-22.

Miller, H.I. (1994) A need to reinvent biotechnology regulation at the EPA. Science 266, 1815-1818.

Munson, A. (1993) Genetically manipulated organisms: international policy-making and implications. International Affairs 69, 497-517.

NRC (National Research Council) (1983) Risk Assessment in the Federal Government: Managing the Process. National Academy Press, Washington, DC.

NRC (National Research Council) (1996) Understanding Risk: Informing Decisions in a Democratic Society. National Academy Press, Washington, DC.

NRC (National Research Council) (2002) Environmental Effects of Transgenic Plants. Committee on Environmental Impacts Associated with Commercialization of Transgenic Plants. Board on Agriculture and Natural Resources: Division on Earth and Life Studies: National Research Council. National Academy Press, Washington, DC.

Nelson, K.C. and Banker, M. (2007) Problem Formulation and Options Assessment Handbook: A Guide to the PFOA Process and How to Integrate it into Environmental Risk Assessment (ERA) of Genetically Modified Organisms (GMOs). University of Minnesota, St Paul, Minnesota and GMO ERA Project. http://www.gmoera.umn.edu (accessed 6 February 2007).

Nelson, K.C., Kibata, G., Lutta, M., Okuro, J.O., Muyekho, F., Odindo, M., Ely, A. and Waquil, J. (2004) Problem formulation and options assessment (PFOA) for genetically modified organisms: the Kenya case study. In: Hilbeck, A. and Andow, D.A. (eds) Risk Assessment of Transgenic Crops: A Case Study of Bt Maize in Kenya. CAB International, Wallingford, UK, pp. 57-82.

Susskind, L., McKearnan, S. and Thomas-Larmer, J. (1999) The Consensus Building Handbook: A Comprehensive Guide to Reaching Agreement. Sage Publications, Thousand Oaks, California. 